\title{
On Numerical Simulation of Black Carbon (Soot) Emissions from Non-Premixed Flames
}

\author{
Ajit Patki1, Xianchang Li1', Daniel Chen², Helen Lou', Peyton Richmond2, Vijaya Damodara', \\ Lan Liu' ${ }^{2}$, Kader Rasel ${ }^{2}$, Arokiaraj Alphones ${ }^{2}$, Jenny Zhou ${ }^{1}$ \\ ${ }^{1}$ Department of Mechanical Engineering, Lamar University, Beaumont, TX, USA \\ ${ }^{2}$ Dan F. Smith Department of Chemical Engineering, Lamar University, Beaumont, TX, USA \\ Email: xli2@lamar.edu
}

Received May 2014

\begin{abstract}
Soot emissions (PM 2.5) from land-based sources pose a substantial health risk, and now are subject to new and tougher EPA regulations. Flaring produces significant amount of particulate matter in the form of soot, along with other harmful gas emissions. A few experimental studies have previously been done on flames burning in a controlled condition. In these lab-experiments, great effort is needed to collect, sample, and analyze the soot so that the emission rate can be calculated. Soot prediction in flares is tricky due to variable conditions such as radiation and surrounding air available for combustion. Work presented in this paper simulates some lab-scale flares in which soot yield for methane flame mixture was measured under different conditions. The focus of this paper is on soot modeling with various flair operating conditions. The computational fluid dynamics software ANSYS Fluent 13 is used. Different soot models were explored along with other chemistry mechanisms. The effect of radiation models, quantity of air supplied, different fuel mixture and its effect over soot formations were also studied.
\end{abstract}

\section{Keywords}

Numerical Modeling, Soot Emission, Flames

\section{Introduction}

Flaring is widely used in many industries to dispose unwanted combustion gases by burning them. Satellite imagery analysis suggests more than 139 billion cubic meters of gas were flared worldwide in 2008 [1]. Industrial flares are one of the measure sources of black carbon i.e. soot. Despite the very high amount of gas flared all over the world and the requirement to report associated emissions, an analysis of the very few existing black carbon (PM) emission factors has revealed that current estimation of black carbon production from industrial flares must be interpreted with cautiousness. Soot is considered as a significant health hazard mainly because its small size [2] and it has been linked to serious respiratory, reproductive, and developmental effects in humans [3]. Soot has also been recognized as a significant source of anthropogenic radiative forcing of the planet's surface [4]-[6]. Measurement of soot emitted by industrial flares with experimental methods is relatively expensive and complex. Johnson et al. [7] in Carleton University, Canada conducted a series of methane mixture flare ex-

How to cite this paper: Patki, A., Li, X. C., Chen, D., Lou, H., Richmond, P., Damodara, V., Liu, L., Rasel, K., Alphones, A., \& Zhou, J. (2014). On Numerical Simulation of Black Carbon (Soot) Emissions from Non-Premixed Flames. Journal of Geoscience and Environment Protection, 2, 15-24. http://dx.doi.org/10.4236/gep.2014.24003 
periments to measure black carbon i.e. soot. These quantitative soot emission measurements were performed on lab-scale flares for a range of burner diameters, exit velocities and fuel compositions.

Computational fluid dynamics (CFD) can be used to predict soot yield from any flare. The key objective of this paper is to simulate a lab-scale flare and analyze the soot data. It is desired that with a certain soot model the numerical method can reasonably predict the soot yield and eventually help the industrials for flare operation. In this paper, the computational fluid dynamics (CFD) is applied to quantitatively analyze the soot yield from nonpremixed flames by using basic physics, turbulence and chemistry models and reliable soot model. The commercial software package, ANSYS Fluent 13.0, is used for this purpose. The effect of radiation models and quantity of air supplied was studied. Soot yield from flame under variable conditions is examined.

\section{Governing Equations and Soot Modeling}

\subsection{Conservation Equations}

The 3D time-averaged steady-state Navier-Stokes equations as well as the equations for mass conservation and energy transports need to be solved. In addition, the species transport and chemical reactions need to be considered too. Because the time-averaged Navier-Stokes equations cannot take the turbulence fluctuation directly, a turbulent model is needed. For industrial application, the $k-\varepsilon$ model is one of popular turbulence models. The $k-\varepsilon$ model consists of two transport equations, which need to be solved to compute the Reynolds stresses given by

$$
\rho \overline{u_{i}^{\prime} u_{j}^{\prime}}=\frac{2}{3} \rho k \delta_{i j}+\left[\mu_{t}\left(\frac{\partial u_{i}}{\partial x_{j}}+\frac{\partial u_{j}}{\partial x_{i}}\right)\right]
$$

where $\mu_{t}$ is the eddy kinematic viscosity, $\delta_{i j}$ is the Kronecker delta and $k$ is the kinetic energy of turbulence. The $u_{i}^{\prime}$ and $u_{j}^{\prime}$ represent the fluctuating velocity in different directions. The two transport equations of this model can be given as.

$$
\begin{gathered}
\frac{\partial(\rho k)}{\partial t}+\frac{\partial}{\partial x_{i}}\left(\rho u_{i} k\right)=\frac{\partial}{\partial x_{i}}\left[\left(\mu+\frac{\mu_{t}}{\sigma_{k}}\right) \frac{\partial k}{\partial x_{i}}\right]+G_{k}-\rho \varepsilon \\
\frac{\partial(\rho \varepsilon)}{\partial t}+\frac{\partial}{\partial x_{i}}\left(\rho u_{i} \varepsilon\right)=\frac{\partial}{\partial x_{i}}\left[\left(\mu+\frac{\mu_{t}}{\sigma_{\varepsilon}}\right) \frac{\partial \varepsilon}{\partial x_{i}}\right]+C_{1} \frac{\varepsilon}{k} G_{k}+C_{2} \rho \frac{\varepsilon^{2}}{k}
\end{gathered}
$$

where $C_{1}, C_{2}, \sigma_{k}$ and $\sigma_{\varepsilon}$ are empirical constants. $G_{k}$ is the generation term for turbulence. The turbulent viscosity can be calculated by.

$$
\mu_{t}=\rho C_{\mu} \frac{k^{2}}{\varepsilon}
$$

where the constant $C_{\mu}=0.09$.

The species equation is a statement of conservation of a single species. The conservation equation for the mass fraction $\left(m_{i}^{\prime}\right)$ of species $i^{\prime}$ is given by

$$
\frac{\partial\left(\rho m_{i^{\prime}}\right)}{\partial t}+\frac{\partial}{\partial x_{i}}\left(\rho u_{i} m_{i^{\prime}}\right)=-\frac{\partial}{\partial x_{i}} J_{i^{\prime}, i}+R_{i^{\prime}}+S_{i^{\prime}}
$$

where $J_{i^{\prime}, i}$ is the $i^{\text {th }}$ component of the diffusion flux of species $i^{\prime}$ in the mixture, $R_{i^{\prime}}$ is the net rate of production of species $i^{\prime}$ by chemical reaction and $S_{i^{\prime}}$ is the source term from the dispersed phase or any user defined source.

\subsection{Soot Models}

The Moss-Brookes model solves transport equations for normalized radical nuclei concentration $b_{n u c}^{*}$ and soot mass fraction $Y_{\text {soot }}$ :

$$
\frac{\partial\left(\rho Y_{\text {soot }}\right)}{\partial t}+\frac{\partial}{\partial x_{i}}\left(\rho u_{i} Y_{\text {soot }}\right)=\frac{\partial}{\partial x_{i}}\left(\frac{\mu_{t}}{\sigma_{\text {soot }}} \frac{\partial Y_{\text {soot }}}{\partial x_{i}}\right)+\frac{d M}{d t}
$$




$$
\frac{\partial\left(\rho b_{n u c}^{*}\right)}{\partial t}+\frac{\partial}{\partial x_{i}}\left(\rho u_{i} b_{n u c}^{*}\right)=\frac{\partial}{\partial x_{i}}\left(\frac{\mu_{t}}{\sigma_{\text {nuс }}} \frac{\partial b_{\text {nuc }}^{*}}{\partial x_{i}}\right)+\frac{1}{N_{\text {nоrm }}} \frac{d N}{d t}
$$

where $Y_{\text {soot }}$ is soot mass fraction, $M$ is soot mass concentration $\left(\mathrm{kg} / \mathrm{m}^{3}\right), b_{\text {nuc }}^{*}$ is the normalized radical nuclei concentration, and $\mathrm{N}$ is soot particle number density (particles $\left./ \mathrm{m}^{3}\right) . N_{\text {norm }}=10^{15}$ particles.

In the one-step (Khan and Greeves) model, ANSYS Fluent solves a single transport equation for the soot mass fraction:

$$
\frac{\partial\left(\rho Y_{\text {soot }}\right)}{\partial t}+\frac{\partial}{\partial x_{i}}\left(\rho u_{i} Y_{\text {soot }}\right)=\frac{\partial}{\partial x_{i}}\left(\frac{\mu_{t}}{\sigma_{\text {soot }}} \frac{\partial Y_{\text {soot }}}{\partial x_{i}}\right)+R_{\text {soot }}
$$

where $Y_{\text {soot }}$ is soot mass fraction, $\sigma_{\text {soot }}$ is turbulent Prandtl number for soot transport, and $R_{\text {soot }}$ is net rate of soot generation. The default constants for the one-step model are valid for a wide range of hydrocarbon fuels.

The two-step (Tesner) model predicts the generation of radical nuclei and then computes the formation of soot on these nuclei. ANSYS FLUENT therefore solves transport equations for two scalar quantities: the soot mass fraction and the normalized radical nuclei concentration.

$$
\frac{\partial\left(\rho b_{n u c}^{*}\right)}{\partial t}+\frac{\partial}{\partial x_{i}}\left(\rho u_{i} b_{n u c}^{*}\right)=\frac{\partial}{\partial x_{i}}\left(\frac{\mu_{t}}{\sigma_{\text {пис }}} \frac{\partial b_{\text {nuс }}^{*}}{\partial x_{i}}\right)+R_{\text {nuс }}^{*}
$$

where $b_{n u c}^{*}$ is normalized radical nuclei concentration (particles $\times 10^{-15} / \mathrm{kg}$ ), $\sigma_{\text {nuc }}$ is the turbulent Prandtl number for nuclei transport, and $R_{n u c}^{*}$ is the normalized net rate of nuclei generation (particles $\times 10^{-15} / \mathrm{m}^{3} \mathrm{~s}$ ). In these transport equations, the rates of nuclei and soot generation are the net rates, involving a balance between formation and combustion. More details of these models as well as the default coefficients can be found in [8].

\subsection{Chemical Mechanisms}

Numerical simulation of combustion requires a comprehensive reaction kinetics mechanism, which takes care of all the reaction pathways and the species that are produced during and at the end of combustion. CHEMKIN, a reaction engineering software package, was used to develop the reaction mechanism. The 50-species combustion mechanism termed LU 1.0 was reduced from the combined GRI and USC mechanisms. The combined GRIUSC thermo mechanism consists of 93 species, and has to be further reduced to 50 species to satisfy the maximum species limit set by Fluent. The reduction mechanism was validated by sensitivity and the rate of reaction. The detailed mechanism had 93 species and 600 reactions which were reduced in a step wise manner to 50 species and 337 reactions.

\section{Numerical Modeling}

\subsection{Computational Domain and Mesh}

In this study, ANSYS Workbench is used to create the 3D geometry. The concept of flame is shown in Figure $\mathbf{1}$ Air is supplied from the bottom part of cylinder and the fuel inlet is given from stack. The geometry consists of two axially concentric cylinders. One is for main domain and another is for stack inlet. The diameter and height of large cylinder are 0.7 and $2.2 \mathrm{~m}$, respectively, where the diameters and height of stack inlet is $25 \mathrm{~mm}$ and 0.2 $\mathrm{m}$, respectively. The outlet is placed at top of the computational domain.

The mesh is shown in Figure 2. Circular edges of cylinder are divided into 60 equal parts. Whereas the height above stack is divided into 100 parts with bias factor of 12 . Therefore, mesh is denser near stack and less dense away from stack. Side edges near stack are also divided into 26 parts with bias factor of 16 . Mesh is denser at center and less dense away from the center. Once the mesh is build, it is checked for mesh orthogonal quality. Orthogonal quality near to unity is considered as good quality. Therefore mesh orthogonal quality of current geometry is monitored and kept above 0.8 . The mesh used for simulation consists of 0.22 million cells. The simulation was performed on a system with Intel Quad core i5 processors, CPU at $3.2 \mathrm{GHZ}$ and RAM of $8 \mathrm{~GB}$.

\subsection{Boundary Conditions and Numerical Procedures}

The commercial software ANSYS Fluent 13.0 is used for simulation. Gravity is applied in negative Y-axis as 


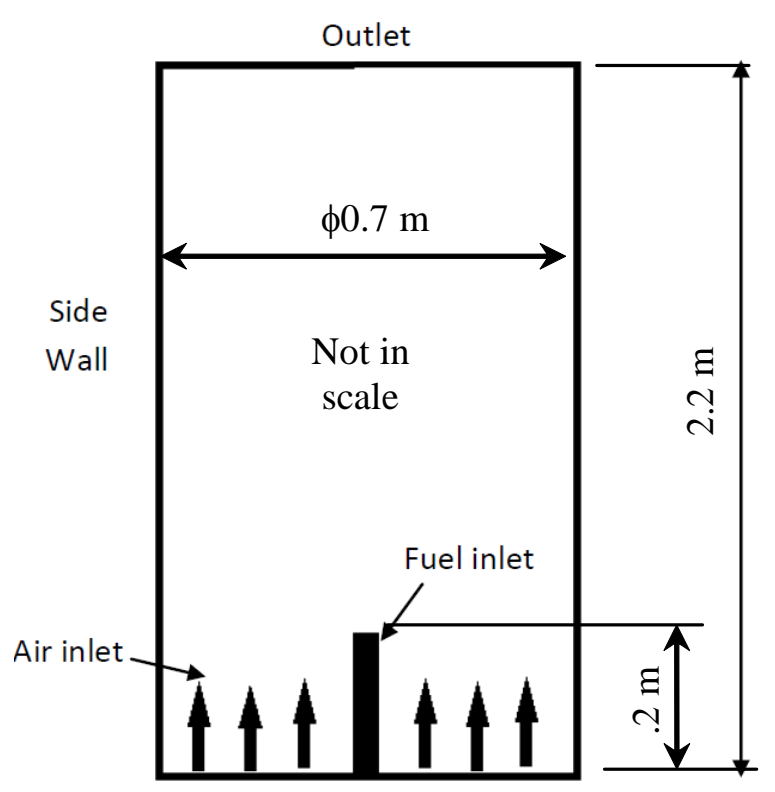

Figure 1. Concept of flame and computational domain.

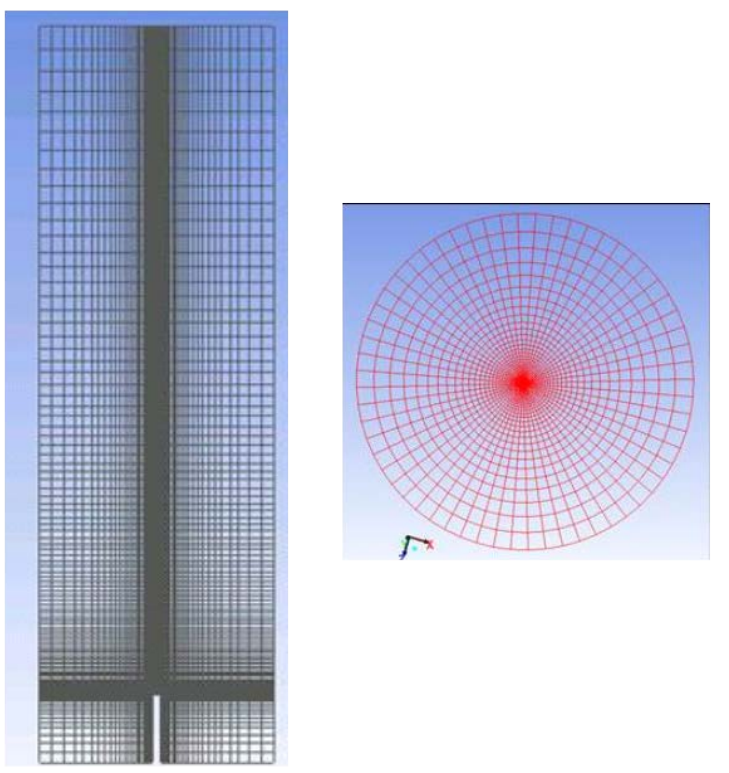

Figure 2. Mesh in different views.

$-9.81 \mathrm{~m} / \mathrm{s}^{2}$. The standard $k-\varepsilon$ model with standard wall functions is used as viscous model. SIMPLE algorithm is enabled for pressure-velocity coupling. The non-premixed combustion species model (PDF model) is used to simulate the combustion process. The CHEMKIN kinetic reaction mechanism file and 93 thermo file are imported to the fluent by using CHEMKIN Import. Two types of fuel are considered and the fuel composition is given in Table 1. Mixture 1 is used for most of the cases while Mixture 2 is used to study the effect of fuel composition on soot generation.

Once fuel is specified, flamelets are generated until either the maximum number of flamelets is reached or the flamelets are extinguished. Extinguished flamelets are not included in library. In ANSYS Fluent, the flamelets can be either generated by the users or imported from other packages. The parameters used for flamelet generation are listed in Table 2. These parameters are limited by computer memory and a fatal error may occur if the parameters are increased beyond a certain level. 
Table 1. Fuel composition.

\begin{tabular}{ccc}
\hline Fuel & Mixture 1 & Mixture 2 \\
\hline $\mathrm{CH}_{4}$ & $73.00 \%$ & $91.00 \%$ \\
$\mathrm{C}_{2} \mathrm{H}_{6}$ & $12.00 \%$ & $4.11 \%$ \\
$\mathrm{C}_{3} \mathrm{H}_{8}$ & $9.57 \%$ & $3.00 \%$ \\
$\mathrm{CO}_{2}$ & $3.28 \%$ & $1.14 \%$ \\
$\mathrm{~N}_{2}$ & $2.15 \%$ & $0.75 \%$ \\
\hline
\end{tabular}

Table 2. Flamelet generation parameters.

\begin{tabular}{cc}
\hline Number of grid points in flamelet & 100 \\
Maximum number of flamelets & 30 \\
Initial scalar dissipation (1/s) & 0.01 \\
Scalar dissipation step (1/s) & 5 \\
\hline
\end{tabular}

The grid refinement was used while generating the flamelets. ANSYS Fluent has the option for automated grid refinement of steady flamelets. An adaptive algorithm inserts grid points so that the change of values as well as the change of slopes between successive grid points is less than user specified tolerances. During automated grid refinement, a steady solution is calculated on a coarse grid with a user specified initial number of grid points in flamelets. When it reaches to the convergence, a new grid point is inserted between a point $i$ and its neighbor $(i+1)$ if it satisfies a certain condition. The parameters for automated grid refinement are listed in Table 3.

After the flamelets are generated, the flamelet profiles are convoluted with the assumed-shape PDFs and then tabulated for look-up in ANSYS Fluent. The parameters used to generate the PDF table are listed in Table 4.

In addition to those settings described above, the operating pressure, temperature and gravity need to be applied. Before starting each case, the solution was initialized from the co-flow inlet. An iso-surface $(Z=0)$ parallel to $\mathrm{X}-\mathrm{Y}$ plane was created at the center of domain. The maximum temperature at $\mathrm{Z}=0$ plane was monitored during iteration. Once the temperature was stabilized and the solution was converged the results were saved for further analysis. The emission is measured at the top surface (outlet) of the domain.

\section{Results and Discussion}

\subsection{Baseline Case}

By applying the settings explained in above section, the baseline case with $0.5 \mathrm{~m} / \mathrm{s}$ jet velocity (fuel inlet velocity) is studied first. Air is supplied from the air inlet at $0.25 \mathrm{~m} / \mathrm{s}$. After some preliminary studies, the MossBrooke soot model is chosen. The radiation effect is not ignored for the baseline case. Figure $\mathbf{3}$ shows the temperature contours along different cross section. It can be said that the highest temperature of the flame is around $1720 \mathrm{~K}$. The height of the flame is approximately $1.1 \mathrm{~m}$.

Figure 4 shows the velocity vector and soot fraction contour. Soot is produced approximately $0.5 \mathrm{~m}$ above the stack. Its peak is located almost the same as the maximum temperature. To compare the soot formation for different cases, flow rate of soot is calculated at the outlet and the flow rate of fuel is calculated at inlet. Soot yield $(\mathrm{kg} / \mathrm{kg})$ is calculated by using following formula.

$$
\text { Soot Yield }=\frac{\text { flow rate of soot at outlet }(\mathrm{kg} / \mathrm{s})}{\text { flow rate of fuel at inlet }(\mathrm{kg} / \mathrm{s})}
$$

The soot yield as well as other parameters is given in Table 5.

\subsection{Effect of Soot Models}

It is not easy to model the soot generation accurately. Fluent gives three soot models: One-step soot model, two-step soot model, and Moss-Brooks soot model. To explore the difference among these models, all parame- 
Table 3. Grid refinement parameters for flamelet.

\begin{tabular}{cc}
\hline Initial number of grid points in flamelet & 8 \\
Maximum number of grid points in flamelet & 64 \\
Maximum change in value ratio & 0.5 \\
Maximum change in slope ratio & 0.5 \\
\hline
\end{tabular}

Table 4. Parameters used to generate the PDF table.

\begin{tabular}{cc}
\hline $\begin{array}{c}\text { Number of mean mixture fraction points } \\
\text { Number of mixture fraction variance points }\end{array}$ & 80 \\
Maximum number of species & 40 \\
Number of mean enthalpy points & 19 \\
Minimum temperature $(\mathrm{k})$ & 41 \\
\hline
\end{tabular}

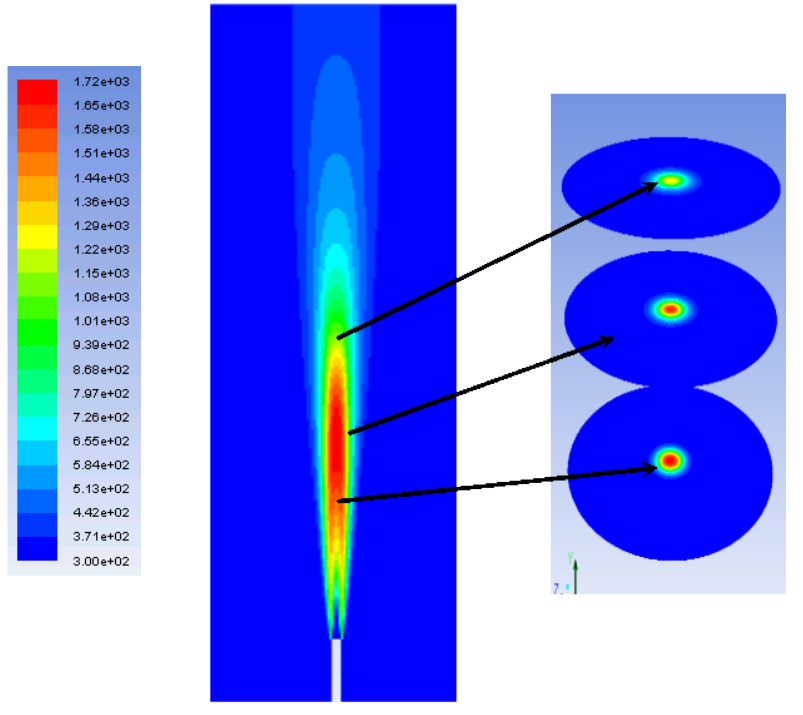

Figure 3. Temperature contour of the baseline case.

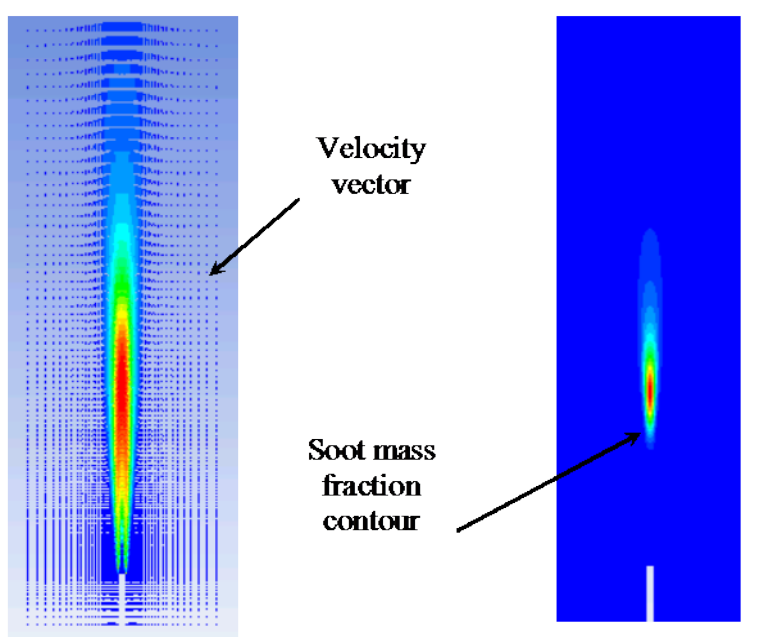

Figure 4. Velocity vectors and soot contours of the baseline. 
ters of the baseline case are kept the same but soot model. Different soot models are applied and soot yield results are presented in Table 6. From results of the flow rate of soot at outlet, it can be said that One-step and two-step soot models give very low values for soot yield. However, the Moss-Brooks model gives a reasonable soot yield, i.e. closer to the experimental results in [7].

\subsection{Effect of Air Velocities}

It is known that air supply affects the combustion process and thus the soot generation. To understand how important the air supplied is, the baseline case is tried with different air velocities. The temperature and soot results are presented in Table 7. From these results, it can be inferred that soot yield also increases as air supplied increases. Also there is a slight rise in flame temperature with higher air velocity.

\subsection{Effect of Chemical Mechanisms}

For the chemical reactions, Fluent has an equilibrium option with which no mechanism is needed. In such case, Fluent non-premixed model (i.e. PDF model) uses its own mechanism which contains 20 species. There is no need to use flamelet model if this equilibrium option is taken. To examine the impact of chemical mechanism, the baseline case is repeated with the equilibrium option where the flamelet is not generated. Its results are compared to those with flamelets. As listed in Table 8, the model without mechanism and flamelet gives very low soot yield at outlet. Also the maximum temperature attained by flame is relatively lower than that with flamelet.

\subsection{Soot Yield with Different Fuel Mixture}

To further understand the behavior of soot models in Fluent, the second type of fuel is studied. The details of fuel composition are given earlier in Table 1. The results are compared to the baseline case. As seen in Table 9, soot yield results are significantly lower for Mixture 2, which is because Mixture 2 has more methane (91\%) than Mixture 1 (73\%). There is more carbon in Mixture 1 and more carbon means higher potential for soot yield. Also the maximum flame temperature attained by Mixture 2 flame is slightly lower than that with Mixture 1 .

\subsection{Effect of Radiation on Soot Yield}

In all the cases so far, the effect of radiation is neglected. In this section, radiation is considered to examine how it is important to soot yield. As an initial attempt, P-1 radiation model is enabled. The P-1 radiation model is the simplest case of the more general P-N model, which is based on the expansion of the radiation intensity into an orthogonal series of spherical harmonics. The results are presented in Table $\mathbf{1 0 .}$

From Table 10, it is seen that soot yield at the outlet for both cases is almost same. Also, the maximum flame temperature differs only slightly. Therefore, it can be concluded that radiation does not make any big difference in soot yield or the maximum temperature attained by the flame.

Table 6. Soot yield results for three different soot models.

\begin{tabular}{ccc}
\hline Soot model & Flow rate of soot at outlet $(\mathrm{kg} / \mathrm{s})$ & Soot yield $(\mathrm{kg} / \mathrm{kg})$ \\
\hline One step & $1.41 \times 10^{-12}$ & $7.42 \times 10^{-9}$ \\
Two step & $1.72 \times 10^{-19}$ & $9.05 \times 10^{-16}$ \\
Moss-Brooke & $1.40 \times 10^{-6}$ & 0.0073 \\
\hline
\end{tabular}

Table 7. Soot yield results for different air velocities.

\begin{tabular}{cccc}
\hline Air velocity $(\mathrm{m} / \mathrm{s})$ & Soot at outlet $(\mathrm{kg} / \mathrm{s})$ & Soot yield $(\mathrm{kg} / \mathrm{kg})$ & Max temp $(\mathrm{K})$ \\
\hline $\mathbf{0 . 2 5}$ & $1.40 \times 10^{-6}$ & 0.0073 & 1720.5 \\
$\mathbf{0 . 5}$ & $1.77 \times 10^{-6}$ & 0.0092 & 1736.1 \\
$\mathbf{0 . 7 5}$ & $2.20 \times 10^{-6}$ & 0.0115 & 1750.8 \\
$\mathbf{1}$ & $2.83 \times 10^{-6}$ & 0.0148 & 1765.1 \\
\hline
\end{tabular}




\subsection{Effect of Fuel Jet Velocity}

To examine the soot formation with different jet velocity or fuel flow rate, five more jet velocities are considered. All the other parameters are kept the same. These jet velocities are $0.1,0.25,0.9,1.5$, and $2.2 \mathrm{~m} / \mathrm{s}$. Figure 6 shows the temperature contours through the centerline in the vertical direction for all the cases with different jet velocities, and Table $\mathbf{1 1}$ gives details of soot yield and flame temperatures.

It is observed that height of the flame increased as jet velocity increases due to the big momentum with high velocity. When the velocity is high, the computational domain can be too short to complete all the chemical reactions. In addition, it is observed that the flame temperature increases slightly with increase in jet velocity. However, the rate of soot emission increases significantly when the velocity increases, which is actually against the study by McEwen and Johnson [7]. In their experiments, McEwen and Johnson [7] found that the soot yield reaches a maximum and then drops when the jet velocity further increases. More studies are needed to explore the difference. The contours of soot mass fraction are given in Figure 7, which shows the peak region moves up with increase in jet velocity.

\section{Conclusion}

Based on the numerical results in this study, it can be concluded that, among three different soot models, the Moss-Brooke model provides more reasonable results for methane mixture flame. The study also indicates that when more air is supplied, the soot yield is higher. As expected, results with different fuel mixture advocate that

Table 8. Soot yield with different chemical mechanisms.

\begin{tabular}{cccc}
\hline Models & Soot flow rate $(\mathrm{kg} / \mathrm{s})$ & Soot yield $(\mathrm{kg} / \mathrm{kg})$ & Max temp (K) \\
\hline Without Flamelet & $2.18 \times 10^{-9}$ & 0.000015 & 1677.1 \\
With Flamelet & $1.40 \times 10^{-6}$ & 0.007361 & 1720.5 \\
\hline
\end{tabular}

Table 9. Soot yield for two different fuel mixtures.

\begin{tabular}{cccc}
\hline Fuel Mixture & Soot at exit $(\mathrm{kg} / \mathrm{s})$ & Soot yield $(\mathrm{kg} / \mathrm{kg})$ & Max temp $(\mathrm{K})$ \\
\hline Mixture $1\left(73 \% \mathrm{CH}_{4}\right)$ & $1.401 \times 10^{-6}$ & 0.00736 & 1720.5 \\
Mixture 2 $\left(91 \% \mathrm{CH}_{4}\right)$ & $1.479 \times 10^{-7}$ & 0.00074 & 1697.6 \\
\hline
\end{tabular}

Table 10. Comparison of cases with and without radiation.

\begin{tabular}{cccc}
\hline Model & Soot at exit $(\mathrm{kg} / \mathrm{s})$ & Soot yield $(\mathrm{kg} / \mathrm{kg})$ & Max temp (K) \\
\hline Without radiation & $1.401 \times 10^{-6}$ & 0.0073 & 1720.5 \\
With radiation & $1.374 \times 10^{-6}$ & 0.0072 & 1717.6 \\
\hline
\end{tabular}

Table 11. Soot yield and maximum temperature for different jet velocities.

\begin{tabular}{ccc}
\hline Jet velocity $(\mathrm{m} / \mathrm{s})$ & Soot yield $(\mathrm{kg} / \mathrm{kg})$ & Max temperature $(\mathrm{K})$ \\
\hline 0.1 & 0.0006 & 1590 \\
0.25 & 0.0022 & 1670 \\
0.5 & 0.0073 & 1720 \\
0.9 & 0.0160 & 1749 \\
1.5 & 0.0273 & 1768 \\
2.2 & 0.0377 & 1778 \\
\hline
\end{tabular}



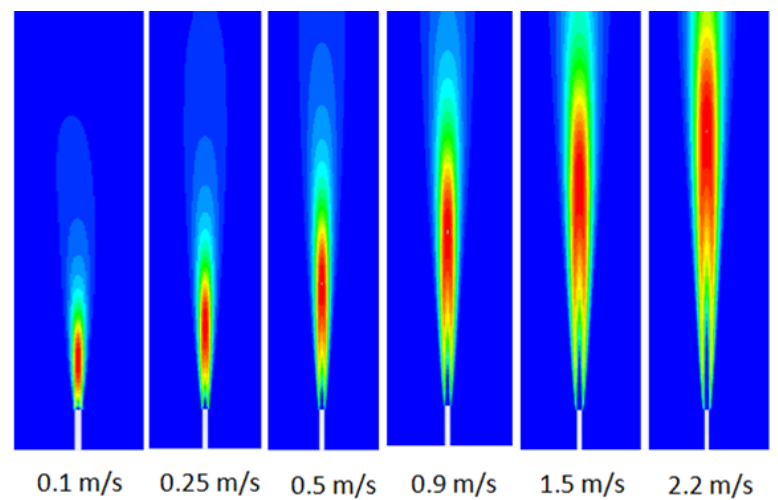

Figure 6. Flame temperature with different jet velocities.



$0.1 \mathrm{~m} / \mathrm{s}$

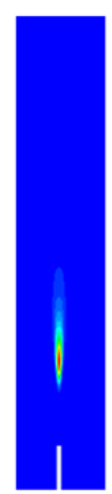

$0.25 \mathrm{~m} / \mathrm{s}$

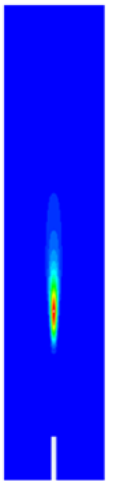

$0.5 \mathrm{~m} / \mathrm{s}$



$0.9 \mathrm{~m} / \mathrm{s}$

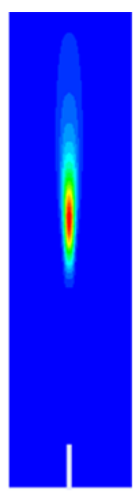

$1.5 \mathrm{~m} / \mathrm{s}$

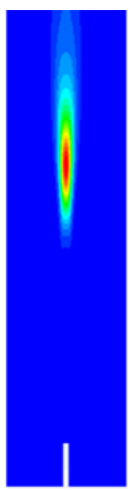

$2.2 \mathrm{~m} / \mathrm{s}$

Figure 7. Soot formation with different jet velocities.

soot yield increases as carbon percentage in fuel increases. Furthermore, it can be inferred that, the equilibrium model provided in Fluent produces significantly lower soot yield than LU 1.0 mechanism steady flamelet model. By using P-1 radiation model it is seen that the radiation effect is negligible on methane mixture soot yield and flame temperature. Finally, soot yield results with different jet velocities propose that soot yield increases as jet velocity increases. In the meantime the flame maximum temperature also increases slightly when the jet velocity becomes higher.

\section{Acknowledgements}

This work is partially supported by the Texas Commission of Environmental Quality and the Texas Air Research Center.

\section{References}

(2010). US EPA Integrated Science Assessment for Particulate Matter EPA/600/R-08/139F. Washington DC.

Elvidge, C. D., Ziskin, D., Baugh, K. E., Tuttle, B. T., Ghosh, T., Pack, D. W., Erwin, E. H., \& Zhizhin, M. (2009). A Fifteen Year Record of Global Natural Gas Flaring Derived from Satellite Data. Energies, 2, 595-622. http://dx.doi.org/10.3390/en20300595

Fluent Manual (2006). Version 6.2.36. Fluent, Inc.

Hansen, J., Sato, M., Ruedy, R., Lacis, A., \& Oinas, V. (2000). Global Warming in the Twenty-First Century: An Alternative Scenario. Proceedings of the National Academy of Sciences of the United States of America, 97, 9875-9880. http://dx.doi.org/10.1073/pnas.170278997

McEwen, J. D. N., \& Johnson, M.R. (2012). Black Carbon Particulate Matter Emission Factors for Buoyancy Driven Associated Gas Flares. Journal of the Air \& Waste Management Association, 62, 307-321.

http://dx.doi.org/10.1080/10473289.2011.650040 
Pope III, C. A., Burnett, R. T., Thun, M. J., Eugenia, E. C., Krewski, D., Ito, K., \& Thruston, G. D. (2002). Lung Cancer, Cardiopulmonary Mortality, and Long-Term Exposure to Fine Particulate Air Pollution. JAMA: The Journal of the American Medical Association, 287, 1132-1141. http://dx.doi.org/10.1001/jama.287.9.1132

Ramanathan, V., \& Carmichael, G. (2008). Global and Regional Climate Changes Due to Black Carbon. Nature Geoscience, 1, 221-227. http://dx.doi.org/10.1038/ngeo156

Solomon, S., Qin, D., Manning, M., Chen, Z., Marquis, M., Averyt, K. B., Tignor, M., \& Miller, H. L. (2007). Contribution of Working Group I to the Fourth Assessment Report of the Intergovernmental Panel on Climate Change (p. 996). Cambridge: Cambridge University Press. 